\title{
Plano de Ações Articuladas: avaliação da aprendizagem e sua interface com a avaliação externa
}

Lucia de Fatima Valente
Universidade Federal de Uberlândia
Luciane Terra dos Santos Garcia
Gilneide Maria de Oliveira Lobo
Universidade Federal do Rio Grande do Norte

\section{Resumo}

Este estudo analisa as ações do Plano de Ações Articuladas - PAR, voltadas para a área de avaliação da aprendizagem contidas na Dimensão 3, denominada Práticas Pedagógicas e Avaliação, no período de 2007 a 201 1, enfocando municípios do estado do Rio Grande do Norte. Trata-se de uma pesquisa teórico-empírica que utilizou metodologia de cunho qualitativo. Como procedimentos, foram utilizadas análise bibliográfica e documental bem como entrevistas semiestruturadas junto aos responsáveis das Secretarias Municipais. Quanto à avaliação da aprendizagem, o PAR tem levado à implementação de ações referentes à definição de concepção de avaliação da rede de ensino, assistência aos estudantes e correção de fluxo escolar, no entanto, os dados revelam a responsabilização das instituições de ensino em relação aos seus resultados sem apontar as políticas e as condições materiais para que a "qualidade" e o direito à aprendizagem se efetivem.

Palavras-chave: Avaliação da aprendizagem. Avaliação externa. Plano de Ações Articuladas.

\section{Articulated Action Plan: the learning assessment and its interface with the extern evaluation}

\section{Abstract}

This study analyzes the actions of the Articulated Action Plan - PAR devoted to the area of Learning Assessment that are inside its Dimension 3, denominated Pedagogical Practices and Assessment, at the period of 2007 to 2011 , in municipalities of Rio Grande do Norte. This is a theory-empiric research that used a qualitative methodology. As research procedures, were used bibliographical and documental analysis and semi-structured interviews with the responsible people of the Municipal Secretaries. In relation to the learning assessment, the PAR has brought to the implementation of actions referring to the definition of the conception of the learning network assessment, student assistance, and scholar flow correction. The responsibility of the actions, however, becomes to the professionals despite the network does not offer the necessary conditions for changes.

Keywords: Learning assessment. Extern evaluation. Articulated Actions Plan. 
Plano de Ações Articuladas: avaliação da aprendizagem e sua interface com a avaliação externa

\section{Plano de Acciones Articuladas: evaluación del aprendizaje y su inter- face con la evaluación externa}

\section{Resumen}

Este estudio analiza las acciones del Plan de Acciones Articuladas - PAR volcadas hacia el área de evaluación del aprendizaje contenidas en la Dimensión 3, denominadas Prácticas Pedagógicas y de Evaluación. Para ello, se presentan resultados de la pesquisa Evaluación del Plano de Acciones Articuladas-PAR: un estudio en municipios de los estados de Rio Grande do Norte, Pará y Minas Gerais en el periodo de 2007 a 2011 pero en este trabajo, enfocamos sólo municipios de Rio Grande do Norte. Se trata de una pesquisa teórico-empírica que ha utilizado metodología de cuño cualitativo. Como procedimientos han sido utilizados análisis bibliográficos y documentales así como entrevistas semiestructuradas con responsables de las Secretarías Municipales. En cuanto a la evaluación del aprendizaje, el PAR ha llevado a la implementación de acciones referentes a la definición de concepto de evaluación en la red de enseñanza, asistencia a los estudiantes y corrección del flujo escolar sin embargo, la responsabilidad de las acciones recae sobre los profesionales, sin que la red orezca las condiciones necesarias para el cambio.

Palabras clave: Evaluación del aprendizaje. Evaluación externa. Plano de Acciones Articuladas.

\section{Introdução}

Plano de Ações Articuladas (PAR), instituído por meio do Plano de Desenvolvimento da Educação (PDE), em 2007 (BRASIL, 2007a), com base na adesão ao Plano de Metas Compromisso Todos pela Educação (PMCTE) (BRASIL, 2007b), é um plano estratégico que deve ser construído para um período de quatro anos, contendo o diagnóstico da situação educacional local dos estados e municípios. Esse plano contempla quatro dimensões referentes a áreas estratégicas para a consolidação da melhoria da qualidade educacional: 1. Gestão Educacional; 2. Formação de Professores e Profissionais de Apoio Escolar; 3. Práticas Pedagógicas e Avaliação; 4. Infraestrutura e Recursos pedagógicos (BRASIL, 2007b). Tais dimensões compreendem as áreas de atuação e indicadores específicos para cada uma das áreas.

Nessa perspectiva, este estudo analisa as ações do PAR, referentes à área de avaliação da aprendizagem, contidas na Dimensão 3 desse plano, denominada Práticas Pedagógicas e Avaliação. Assim, apresentam-se resultados da pesquisa "Avaliação do Plano de Ações Articuladas - PAR: um estudo em municípios dos estados do Rio Grande do Norte, Pará e Minas Gerais, no período de 2007 a 201 1". Esse estudo foi desenvolvido no âmbito do 
Observatório da Educação, em parceria com as Universidades Federais do Rio Grande do Norte - UFRN, do Pará - UFPA e de Uberlândia - UFU. A pesquisa investiga quinze municípios, sendo cinco de cada estado participante. Neste trabalho, enfocam-se os municípios do Rio Grande do Norte: Acari, Mossoró, Natal, Riachuelo e São José do Campestre.

Tem como foco as ações desenvolvidas por esses municípios visando à implementação dos respectivos Planos de Ações Articuladas, referente aos indicadores: "Formas de avaliação da aprendizagem dos alunos", "Utilização do tempo para assistência individual/coletiva aos alunos que apresentam dificuldade de aprendizagem" e "Política específica de correção de fluxo". Ademais, buscar-se-á compreender a relação entre a implementação desses indicadores e as políticas de avaliação externa às escolas implementadas no país.

Realizou-se uma pesquisa teórico-empírica, com metodologia de cunho qualitativo, que, segundo Minayo (1999), incorporam intencionalidades referentes às relações humanas, às estruturas sociais, à compreensão de significados, como um conceito integrante da totalidade. Isso porque, conforme Bogdan e Biklen (1997), a ação humana deve ser compreendida a partir dos significados que os sujeitos thes atribuem.

Como procedimentos, foram utilizadas a análise bibliográfica e documental, bem como entrevistas semiestruturadas. A análise bibliográfica foi feita a partir de autores como Dias Sobrinho (2002, 2003), Fernandes (2009), Sordi (2009) Freitas (2007, 2011 ) e Ravitch (2011) que discutem temáticas da política educacional, avaliação de sistemas e da aprendizagem.

Para a análise documental, utilizaram-se os marcos legais que regulamentam o planejamento da política educacional brasileira, no período de 2007 a 201 1, como o do Decreto n 6.094/2007, do PDE e do Plano de Metas Compromisso Todos pela Educação (PMCTE). Em âmbito local, foram analisados os Planos de Ações Articuladas de cada município.

Foram entrevistados, além dos secretários de educação de cada um dos municípios, os técnicos que atuaram nas secretarias municipais, responsáveis pelos programas do PAR, no período do estudo. Os entrevistados responderam a questões comuns, a fim de garantir a abordagem dos mesmos temas. A quantidade de informantes variou conforme o município e foram designados por números, conforme a ordem de realização das entrevistas. 
Neste artigo, utilizaram-se os dados específicos da dimensão Práticas Pedagógicas e avaliação, Área 2 - Avaliação da aprendizagem dos alunos e tempo para assistência individual/coletiva aos alunos que apresentam dificuldade de aprendizagem. Todas as entrevistas foram transcritas e, em seguida, utilizada a ferramenta WordSmithTools'. Tais dados foram organizados com base nas respostas dos informantes, em Wordlist, com seleção de palavras significativas, possibilitando, assim, a análise linguística das informações prestadas.

Os questionamentos das entrevistas foram direcionados para possibilitar a compreensão da concepção de avaliação adotada pelos municípios, como assistiam, individualmente, os alunos com dificuldade de aprendizagem e ainda qual política de Correção de Fluxo Escolar era desenvolvida para atender aos alunos com distorção idade/série.

$\mathrm{Na}$ análise dos dados, utilizou-se como categoria analítica a Avaliação da Aprendizagem, tomando como referência teórica o descritor elaborado pelos pesquisadores (AURELIANO et al, 2014). Nele, destaca-se a avaliação da aprendizagem como dimensão do processo de ensino que envolve julgamento de valor e, na perspectiva tradicional, enfatiza a classifica124 ção do desempenho dos alunos por meio de instrumentos utilizados para aferir resultados quantitativos, ao final de período escolar. Em oposição a essa perspectiva, é apresentada a avaliação formativa, dialógica, participante, como concepção que busca regular o ensino e a aprendizagem de forma processual e contínua.

Este artigo está organizado em duas seções, além da introdução e das considerações finais. Inicialmente, discutem-se as políticas de avaliação externa, suas configurações e desdobramentos na escola; em seguida, situa-se - Plano de Ações Articuladas (PAR) no contexto das políticas educacionais e analisam-se os resultados da pesquisa acerca da implementação das ações de avaliação da aprendizagem em municípios potiguares.

\section{Políticas de avaliação externas no Brasil: configurações e desdobramentos na escola}

Atualmente, a avaliação tem configurado um dos principais eixos da regulação educacional, constituindo-se em mecanismo de controle e 
distribuição de recursos, visto que o Estado vem atrelando o financiamento da educação aos resultados de índices educacionais. Essa medida advém da redefinição do papel do Estado que passou da condição de Estado Educador para assumir, predominantemente, a concepção de Avaliador. $\bigcirc$ Estado Educador caracteriza-se pela difusão de determinados conhecimentos, valores e visões de mundo da cultura hegemônica. Segundo Dias Sobrinho, como

[...] avaliador ou interventor, o Estado costuma praticar uma avaliação predominantemente controladora e organizadora de suas políticas de distribuição de recursos - diretamente, sob a forma de orçamentos, indiretamente, por meio de premiações e incentivos -, hierarquização institucional com base em resultados de testes de rendimentos e quantificação de produtos, (re)credenciamentos de cursos e acreditation. Em geral, são avaliações externas, somativas, orientadas para o exame dos resultados, realizadas ex poste seguem prioritariamente os paradigmas objetivistas e quantitativistas (DIAS SOBRINHO, 2003, p. 59-60).

Tornar-se avaliador não invalida a sua função educativa, mas passa a ser exercida com base em novos parâmetros, com formas mais fluidas de controle, que privilegiam resultados e responsabilizam os próprios sujeitos. Desde a reforma do Estado brasileiro, nos anos de 1990, essa concepção de Estado adquiriu centralidade, tendo sido instituído um conjunto de políticas de descentralização de poderes e encargos bem como de avaliação dos serviços educacionais, como forma de controle das instâncias descentralizadas. Essa reforma deve ser compreendida como parte de um contexto socioeconômico e político, de um sistema de valores e normas constituídos transnacionalmente, que assume a avaliação como parte dos processos de regulação dos serviços educacionais.

Isso significa que não há, em termos absolutos, um modo "certo" ou "errado" de avaliar; o papel que desempenha, os instrumentos e meios utilizados para aferir uma realidade dependem dos grupos no poder bem como das demandas e necessidades históricas. Trata-se, portanto, de um campo em disputa, com diferentes posições e concepções teóricas.

Para uns, a avaliação deve assumir princípios e critérios baseados na ética, na democracia, na autonomia, visando garantir a eficiência e a qualidade educacional, orientadas para a melhoria dos indicadores sociais, privilegiando, portanto, funções diagnósticas e formativas. Em contraposição, 
existem modelos avaliativos defendidos pelos grupos hegemônicos e implantados pelos órgãos oficiais, voltados para a construção de quase-mercado 2 educacional. Esse tipo de avaliação privilegia princípios e critérios de eficiência, produtividade e competitividade, que prioriza a aferição pontual dos desempenhos dos estudantes e profissionais, articulada ao financiamento da educação.

Essa segunda concepção justifica os nexos que vêm marcando a avaliação educacional no país, visto que privilegiam os produtos e os resultados em detrimento dos processos. De modo geral, não há uma análise dos fatores que influenciam os baixos desempenhos educacionais classificando as escolas em função do mérito. A questão da qualidade está atrelada à lógica competitiva, visto que se acredita que a competição gera qualidade. Inerente a essa lógica de seleção dos mais aptos, está a ideia de exclusão e a naturalização da desigualdade educacionais e sociais.

Essa lógica que privilegia resultados, classifica as escolas com base em seu desempenho e fomenta a competição em seu interior; é a lógica que impulsiona a avaliação no Plano de Desenvolvimento da Educação (BRASIL, 2007a) e, no seu âmbito, o Decreto n 6.094, de 25 de abril de 2007 126 (BRASIL, 2007b). Com esse plano, a avaliação adquiriu maior centralidade, considerando a criação do Indice de Desenvolvimento da Educação Básica (ldeb). Esse índice, de acordo com Fernandes (2007), é considerado um indicador educacional que estabelece relação positiva por conciliar informações do rendimento escolar (aprovação, repetência e abandono) informadas pelo Censo Escolar, com dados do desempenho da aprendizagem, provenientes das avaliações externas - Saeb e Prova Brasil.

Nessa perspectiva, o Saeb e a Prova Brasil funcionariam como instrumentos de avaliação do sistema educacional brasileiro, com a finalidade de auxiliar o desenvolvimento e a implementação de políticas educacionais. Para tanto, avaliam as habilidades e as competências dos alunos do $5^{\circ}$ e do $9^{\circ}$ anos, do ensino fundamental, e $\circ 3^{\circ}$ ano, do ensino médio, em Língua Portuguesa e Matemática. O que os diferencia é o fato de o Saeb ser amostral e abranger escolas públicas e privadas, urbanas e rurais do ensino fundamental e médio. A meta da Prova Brasil, por sua vez, é avaliar os alunos das escolas públicas urbanas, com mais de 20 alunos matriculados nos anos finais dos ciclos do ensino fundamental. 
De acordo com o PDE (BRASIL, 2007a), com a criação do ldeb, o governo deixaria de praticar exame e passaria a fazer avaliação. Esse índice tornou-se, então, referência para o MEC, direcionando recursos e assistência técnica às escolas públicas, vinculados ao plano de metas.

Nos documentos norteadores das políticas implementadas nas últimas três décadas, a avaliação se justifica pela necessidade de responder, satisfatoriamente, às demandas sociais na área de educação e de estabelecer procedimentos ajustados à realidade. A finalidade da avaliação é, portanto, servir como instrumento de planificação e tomada de decisões, na área educativa. Justifica-se, também, pela necessidade de informar, periodicamente, às escolas e à sociedade acercada implementação das políticas e ações adotadas, bem como a respeito dos seus efeitos e repercussões nas redes de ensino.

Freitas (2007) afirma que, fundamentalmente, as avaliações em larga escala devem ser destinadas a avaliar políticas públicas, entretanto as escolas podem e devem fazer uso de seus resultados para se autoavaliarem comparando-se consigo mesmas, com o propósito de apontar caminhos para a superação das dificuldades vivenciadas coletivamente. Por meio da análise do próprio desempenho, ao longo do tempo, os profissionais podem encontrar os meios de potencializar a qualidade do trabalho que desenvolvem.

Não é essa, no entanto, a lógica que orienta as atuais políticas públicas de avaliação. Ao contrário, vigora uma lógica produtivista, subjacente aos modelos de avaliação que privilegiam o fluxo, o rendimento e o escalonamento de posição da escola. Esse ranqueamento intensifica a competição e possibilita o oferecimento de serviços diferenciados aos cidadãos. A ênfase no produto assim como a defesa da meritocracia estimulam a criação de um ethos competitivo no serviço público. Essa orientação tem perpassado por diferentes governos brasileiros, até mesmo os que avançaram nas políticas educacionais nos últimos anos, em razão dos modelos de comparação instituídos pelos organismos multilaterais que definem os parâmetros de referência de qualidade das habilidade e competências a serem adquiridas na escola.

Nessa perspectiva, o setor público deve ajustar aos novos tempos e adotar o modus operandi do setor privado por meio da nova gestão pública. Nesta, o Estado é minimizado, mas sua eficiência é ampliada por meio da publicização de seus atos e para tal finalidade, os serviços públicos devem 
Plano de Ações Articuladas: avaliação da aprendizagem e sua interface com a avaliação externa

ser reformados por pessoas externas ao governo, segundo orientações desses mesmos organismos.

Na realidade investigada, percebe-se uma ausência de articulação entre as políticas de avaliação externa às escolas e as práticas de autoavaliação. Ademais, as avaliações externas às escolas não analisam, com profundidade, os nexos entre os resultados e as desigualdades educacionais e sociais; mesmo assim, responsabilizam as instituições e os profissionais como responsáveis por reverter os baixos índices. Essa responsabilização envolve a medida do desempenho dos estudantes, a publicação e a publicização dos resultados, por meio de relatórios, podendo ser definidas recompensas ou sanções. Conforme Freitas, os

[...] processos de responsabilização são bem amplos e em especial suas consequências atingem todos os níveis da administração, ou seja: a) a administração do sistema educacional, enquanto administração local; b) as escolas, na figura dos diretores; e c) a sala de aula, na figura do professor e do aluno (FREITAS, 201 1, p. 16).

Não obstante a responsabilização dos sujeitos, estudos, pesquisas,

128 experiências nacionais e internacionais têm demonstrado que, embora os índices educacionais se constituam em informações importantes, não têm sido bem aproveitados pelas instituições. Esses resultados não são neutros e envolvem autoridade e relações de poder, que negligenciam aspectos relevantes relacionados aos estudantes, professores e a escola.

Reis (2009), ao relatar a experiência em Portugal, adverte para as limitações e perigos da avaliação. A citada autora, referendando-se em estudiosos do campo, afirma que esta tem limitações técnicas ao se restringir à medida e à quantificação em detrimento de fatores pessoais e sociais que interferem no processo, além de proletarizar o trabalho docente e limitar sua autonomia.

Sousa (2008), em seus estudos sobre usos da avaliação e sua relação com a gestão de políticas públicas, constatou que pouco têm influenciado na formulação de políticas. Afirma que "[...] o gerenciamento do sistema tende a apoiar-se nas estruturas burocráticas não se orientando pelos resultados de desempenho escolares" (SOUSA, 2008, p. 699).

Dessa forma, embora as propostas de avaliação em curso objetivem a melhoria da qualidade da educação, na prática, têm se caracterizado, 
Lucia de Fatima Valente | Luciane Terra dos Santos Garcia | Gilneide Maria de Oliveira Lobo

sobremaneira, como políticas de responsabilização e culpabilização das escolas e dos sujeitos que nelas atuam. A relação entre avaliação e melhoria da qualidade não se constituiu ainda em uma realidade no país, visto que os resultados não têm induzido políticas e práticas nesse sentido, restringindo-se, pois, a um sistema de informação educacional. Assim, "[...] o discurso politicamente correto permanece formalmente ligado ao ideal da igualdade de oportunidades, da qualidade, mas muitas práticas sociais se orientam segundo referências muito diferentes" (DEORUET, 2000/2001, p. 36).

Além da problemática apontada, falta, também, a articulação da avaliação externa com as avaliações pedagógicas realizadas na escola. Assim, de forma mais ampla, é necessário o estabelecimento das políticas educacionais articuladas com as políticas sociais. Nesse sentido, afirma Dias Sobrinho que

[...] faltam elementos de compreensão das bases epistemológicas e éticas e de percepção dos efeitos políiticos e pedagógicos de cada modelo de avaliação. Falta adequação no uso de distintas metodologias transplantadas de diferentes disciplinas aos princípios e objetivos desejados em educação. Ocorre com grande frequência que as avaliações se resumam a acumular informações de acordo com os cânones científicos de algumas disciplinas, mais justapostas que combinadas, como a psicologia, a estatística, a sociologia, e a antropologia, muito pouco oferecendo em termos reflexivos para a compreensão das causalidades e para a elaboração de projetos de superação e emancipação (DIAS SOBRINHO, 2002, p. 61).

A avaliação não deve, portanto, se reduzir a uma prática destinada a apontar e registrar dados, mas se voltar para ações de melhoria do objeto avaliado. Nesse sentido, avaliar implica atitudes além de medir e verificar, não se limitando a constatar determinados dados. Uma avaliação comprometida com a ação deve possibilitar aos professores, gestores e ao sistema educacional ampla visão das reais necessidades dos estudantes e das instituições avaliadas, para que o planejamento e a ação institucional tenham como base o que foi apontado pelo trabalho avaliativo.

As propostas de avaliação educacional implantadas no Brasil, entretanto, são permeadas por ideologias e práticas ajustadas ao mercado. Com isso, assiste-se à fragilidade dos sistemas de avaliação pedagógica, na construção de uma educação de qualidade. Na maioria dos casos, a avaliação 
Plano de Ações Articuladas: avaliação da aprendizagem e sua interface com a avaliação externa

externa às escolas e aos sistemas não está redundando em mudanças significativas na qualidade do ensino, uma vez que têm direcionado as escolas a estreitar currículos, focalizando conhecimentos básicos, que limitam a ação docente (RAVITCH, 2011 ).

Pode-se afirmar que a proposta de avaliação no Plano de Ações Articuladas fundamenta-se por essa lógica, uma vez que atrela a melhoria da qualidade do ensino aos indicadores de desempenho e seus resultados. Assim, a prática pedagógica é direcionada para essa finalidade. Passa-se, portanto, a discutir, acerca da implementação das ações do PAR referentes à avaliação, nos municípios investigados.

\section{Implementação das ações do PAR de avaliação da aprendizagem em municípios potiguares}

No ano de 2007, no Brasil, foi instituído o Plano de Desenvolvimento da Educação (PDE) (BRASIL, 2007a) que se constituiu no plano do executivo, elaborado com o objetivo de dinamizar o regime de colaboração entre os

130 entes federados, por meio de transferências voluntárias de recursos financeiros e assistência técnica para a educação básica. Esse propósito foi consubstanciado pelo Decreto n 6.094, de 25 de abril de 2007 (BRASIL, 2007b), que instituiu o Plano de Metas Compromisso Todos Pela Educação (PMCTE), considerado o programa estratégico que articularia essa colaboração, definindo metas e prevendo ações visando à melhoria da qualidade da educação pública do país.

Com base na adesão ao PMCTE, os entes federados deveriam elaborar o Plano de Ações Articuladas (PAR). Em conformidade com o Decreto $n^{\circ}$ 6.094, de 25 de abril de 2007, o PAR configura "[...] o conjunto articulado de ações, apoiado técnica ou financeiramente pelo Ministério da Educação, que visa ao cumprimento das metas do Compromisso e à observância das suas diretrizes". O apoio técnico e financeiro da União, no âmbito do Plano de Ações Articuladas, deve promover a qualidade da educação básica pública, observadas as metas, as diretrizes e as estratégias do Plano Nacional de Educação.

Processo de construção do PAR (2007-201 1), nos estados, municípios e Distrito Federal, ocorreu em duas etapas: 1) diagnóstico da situação 
educacional; e 2) elaboração do PAR, propriamente dito. As secretarias de educação de cada município e/ou estado formavam uma equipe técnica composta pelo: dirigente municipal da educação; técnicos da secretaria; representantes dos diretores de escolas urbanas e rurais, professores, coordenadores-pedagógicos, quadro técnico-administrativo das escolas, Conselhos Escolares e Conselho Municipal de Educação. Essa equipe tinha a função de, com base no diagnóstico, planejar e desenvolver um conjunto coerente de ações a serem sistematizadas no PAR, visando à melhoria da qualidade da educação. Para isso, recebia assistência técnica do MEC, por meio de profissionais das universidades públicas ou, ainda, das secretarias estaduais de educação (BRASIL, 2008).

A melhoria da qualidade da educação nacional, conforme o Decreto $n^{\circ}$ 6.094, de 25 de abril de 2007 (BRASIL, 2007b), deve ser aferida por meio da elevação do Índice de Desenvolvimento da Educação Básica (ldeb). No art. $3^{\circ}$ (BRASIL, 2007b), está designado que o ldeb será o indicador para a verificação do cumprimento de metas fixadas no termo de adesão ao Compromisso Todos Pela Educação. O ldeb, supostamente, aferiria a melhoria do rendimento escolar e do desempenho dos alunos das escolas públicas brasileiras, considerando os investimentos realizados por meio das ações empreendidas nas dimensões do PAR, colocando, assim, a avaliação da aprendizagem em foco.

Nesse sentido, as ações do PAR, na dimensão referente à avaliação, enfocam quesitos relacionados, à melhoria dos resultados que incidem no cálculo do ldeb. A área 2 "Avaliação da aprendizagem dos alunos e tempo para assistência individual/coletiva aos alunos que apresentam dificuldade de aprendizagem", da dimensão 3, denominada "Práticas pedagógicas e avaliação", é composta por 3 indicadores: 1) Formas de avaliação da aprendizagem dos alunos, 2) utilização do tempo para assistência individual/ coletiva aos alunos que apresentam dificuldade de aprendizagem e 3) política específica de correção de fluxo.

Na perspectiva do MEC, o primeiro indicador induz a rede de ensino a analisar a concepção de avaliação que orienta as práticas escolares; o segundo refere-se à assistência prestada aos estudantes com dificuldades de aprendizagem e o terceiro visa combater um problema histórico da educação brasileira, relativo ao desnivelamento dos estudantes, considerando a relação idade-série em etapas de escolaridade básica. A assistência aos estudantes 
com dificuldades de aprendizagem incidiria nos resultados das avaliações externas às escolas, que compõem o cálculo do ldeb, e a correção de fluxo, nas taxas de rendimento escolar. Dessa forma, o foco das políticas de avaliação promovidas pelo PAR, visam à melhoria dos resultados educacionais apresentados pelas escolas.

Considerando que a avaliação não consiste em uma prática neutra, antes de interrogar acerca do referencial de avaliação da escola, a rede de ensino deve questionar: qual seria a concepção de educação que as orienta? A avaliação consiste em um processo intrínseco à educação, sendo orientada por fundamentos teórico-metodológicos, em consonância com a concepção de sociedade e educação que se busca consolidar.

Conforme Dias Sobrinho (2003), de modo geral, pode-se afirmar a existência de dois modelos de avaliação conflitantes entre si, que, por sua vez, denotam visões de mundo contraditórias. Embora afirmando que, na realidade, esses paradigmas, frequentemente, se combinam e se entrecruzam, o autor localiza, de um lado, as concepções de avaliação tecnológica, originadas com base em visões de mundo mecanicistas; e de outro, as concepções subjetivistas, democráticas ou formativas, que se sustentam em epistemologias

132 subjetivistas e naturalistas.

Ainda conforme o autor (2003), a concepção tecnológica é orientada por uma ética utilitária, pragmática e individualista, uma vez que defende que o progresso resulta da utilização competente de recursos, da gestão racional da ciência e tecnologia, que valoriza os números e os produtos. As avaliações subjetivistas, democráticas ou formativas compreendem a verdade como relativa às experiências, valorizando os processos vividos, os aspectos qualitativos e intuitivos da realidade (DIAS SOBRINHO, 2003).

Os educadores progressistas defendem essa última concepção, compreendendo que o processo avaliativo deve conferir as informações necessárias à consecução da aprendizagem. Nesse aspecto, a avaliação deve se constituir na tarefa necessária ao acompanhamento do processo de ensino-aprendizagem em função dos objetivos propostos coletivamente.

Considerando que, em grande medida, as práticas de avaliação tecnológicas marcam a cultura escolar, modificar essa concepção, na direção de uma avaliação processual, contínua, que (re)oriente o processo de ensino-aprendizagem, requer condições, a exemplo de cursos de formação inicial e 
continuada, materiais e recursos pedagógicos, número adequado de estudantes em sala de aula, além das devidas condições de valorização profissional. Tornar a avaliação formativa não é responsabilidade única dos profissionais, mas demanda, das redes de ensino, condições, sem as quais os esforços docentes estariam comprometidos.

É importante ter clareza acerca do referencial que pauta a ação educativa e avaliativa da rede, que deve ser negociada com os sujeitos, como meio de analisar a coerência entre a teoria e a prática. Na elaboração de seus Planos de Ações Articuladas (PAR), os municípios potiguares foram levados a questionar acerca desse referencial, além de julgar se havia a necessidade de implementar ações para consolidá-lo. Essa reflexão se fez mediante a análise situacional, considerando o indicador "formas de avaliação da aprendizagem dos alunos".

Os municípios de Acari, Mossoró e São José do Campestre julgaram não ser necessário desenvolver ações referentes a esse indicador, ao contrário de Natal e Riachuelo. Conforme informações prestadas pelos informantes da pesquisa, a maioria dos municípios pesquisados adotou a concepção de avaliação contínua, conforme prevê o art. 24, Inciso V, da Lei de Diretrizes e Bases da Educação Nacional, Lei n 9.394, de 20 de dezembro de 1996 (BRASIL, 1996). Segundo a alínea "a" do referido inciso, a avaliação nas escolas brasileiras será "[...] contínua e cumulativa do desempenho do aluno, com prevalência dos aspectos qualitativos sobre os quantitativos e dos resultados ao longo do período sobre os de eventuais provas finais" (BRASIL, 1996).

Assim, o informante $\mathrm{O} 1$ do Município de Natal afirma que, na rede de ensino, o "[...] processo era contínuo, a avaliação contínua"; em Mossoró, o informante 10 demonstra que "[...] hoje já tem documento que a avaliação é contínua"; em Acari, o informante $\mathrm{O} 2$ diz que o processo avaliativo é qualitativo e, para orientar a ação dos professores foi criada uma "[...] ficha com 10 critérios" para avaliar os estudantes bimestralmente"; em Riachuelo, o informante 03 assevera que, na rede de ensino, "[...] sempre se trabalhou com a avaliação contida nos PCNs", que, conforme esse referencial, deve ser "[...] contínua e sistematicamente por meio da interpretação qualitativa do conhecimento construído pelo aluno" (BRASIL, 1997); no que se refere a São José do Campestre, não foi possível obter informações acerca da concepção de avaliação da rede. 
Plano de Ações Articuladas: avaliação da aprendizagem e sua interface com a avaliação externa

Nesse sentido, todas as redes, que responderam ao questionamento, afirmaram que as instituições são orientadas a implementar uma avaliação de cunho formativo. Nessa perspectiva, aferir a aprendizagem tem por finalidade, entre outras, orientar as intervenções docentes no processo educativo visando assegurar a aprendizagem do estudante. Essa concepção revela a necessária articulação que deve existir entre ensino, aprendizagem e avaliação, de modo a compor um todo integrado. De acordo com Fernandes (2009, p. 88-89), isso "[...] permite ou deve permitir, regular o ensino e aprendizagem, utilizar tarefas que, simultaneamente, são para ensinar, aprender, avaliar e contextualizar a avaliação", possibilitando que haja "[...] uma relação muito próxima entre as tarefas de avaliação e as finalidades do ensino".

Apesar dos discursos dos profissionais entrevistados e da imposição legal acerca da avaliação formativa, não é essa concepção que, historicamente, fundamentou a prática avaliativa dos profissionais, mas a tecnológica, de natureza seletiva, classificatória e menos capaz de contribuir para a aprendizagem dos estudantes. Além disso, as avaliações externas a que as escolas são submetidas reforçam essa concepção de modo que, embora as redes de ensino orientem a vivência daavaliação formativa, não implica quese efetive 134 nas escolas.Como mostra o informante 10, de Mossoró:

Antes era aquela de nota, a gente sabe que a avaliação serve para replanejar, mas tem aquela concepção de reprovar, de dizer que o aluno não sabe. A gente tem que ter essa outra visão, que muitos professores ainda não tem. Tem gente que acha que avaliação é só para terminar o ano, dizer quem passou e não passou (INFORMANTE 10, 2015).

Observa-se que os professores resistem em modificar suas concepções de avaliação, sem os devidos investimentos em formação e valorização profissional. Instituir práticas de avaliação formativa requer que os docentes tenham o devido suporte da rede de ensino no que tange à capacitação profissional, ao tempo para planejar e avaliar incluído em sua carga horária de trabalho, número adequado de estudantes por sala, entre outros requisitos. Isso implica investimentos que muitas redes de ensino não estão dispostas a realizar. Assim, apesar de o PAR ter como propósito articular esforços, promovendo a análise da realidade situacional da rede e fomentando que os municípios se responsabilizem por implementar mudanças nas condições escolares, muitos 
não querem ou não podem arcar com os custos, o que influencia a seleção dos indicadores implementados e a seleção das ações a serem executadas.

Apesar das dificuldades existentes para implantar a avaliação contínua nas escolas, somente dois municípios admitiram a necessidade de desenvolver ações nesse sentido. Riachuelo justificou essa intenção pelo fato de suas escolas não possuírem projeto político-pedagógico (RIACHUELO, 2007). Entre as ações previstas no PAR (RIACHUELO, 2007), propõe-se orientar as escolas a elaborar esse projeto, qualificar os profissionais nas áreas de currículo e avaliação bem como subsidiar as instituições com material instrucional acerca da articulação de saberes formais e não-formais. Para implementar as duas últimas ações, contaria com a assistência técnica do MEC (RIACHUELO, 2007), no entanto não houve informações acerca da implementação dessas, no período da pesquisa.

Cruz (2015) demonstra que, no Município de Natal, desde 2001 , buscava-se consolidar uma proposta de avaliação formativa, mas, apesar do trabalho de determinados profissionais da Secretaria de Educação, a rede não tem prestado o necessário suporte aos professores e aos estudantes, tendo em vista subsidiar mudanças nas práticas avaliativas dos profissionais. A rede municipal, por sua vez, alegou a necessidade de implementar "[...] reforço escolar a todos os alunos que apresentam dificuldade de aprendizagem com profissionais que estejam aptos para realizar essa tarefa" (NATAL, 2007, s/p). Justifica que não realizar o reforço escolar influencia os resultados do ldeb, propondo estimular suas escolas à autoavaliação e a desenvolver práticas interdisciplinares. No entanto, ao definir assubações a serem executadas, a rede de ensino propõe-se apenas a orientar as escolas a incluírem a autoavaliação dos estudantes em seus projetos político-pedagógicos, que não demanda grandes investimentos municipais.

Certamente, a autoavaliação consiste em instrumento capaz de auxiliar o estudante a identificar lacunas de conhecimento, mas não se deve reduzir o reforço escolar à autoavaliação do estudante, tampouco a avaliação formativa a essa forma de aferição. Dias Sobrinho (2003, p. 125) esclarece que "[...] mesmo nas autoavaliações podem prevalecer as perspectivas positivistas e os modelos tecnológicos", a depender da finalidade com que é empregada e como se promove a participação. Em uma perspectiva formativa, a autoavaliação da aprendizagem implicaria, entre outros quesitos, a análise do desempenho não só do aluno mas também do professor, aliada a outros 
processos de aferição do processo educativo, que colaborariam para orientar as intervenções docentes visando à construção da aprendizagem.

No instrumento de aferição da rede de ensino há referência, somente, à autoavaliação do estudante o que denota a perspectiva unidirecional que se busca imprimir ao processo avaliativo. Tampouco o PAR apresenta uma opção referente à autoavaliação escolar, com objetivo de fornecer informações necessárias ao planejamento das ações, subsidiando as decisões institucionais. Isso porque se compreende a avaliação conforme a lógica produtivista, que tem como propósito informar a sociedade acerca dos investimentos realizados.

Ademais, nos dois municípios que se propuseram a subsidiar suas escolas na vivência de uma avaliação formativa, essas ações não se efetivaram. Riachuelo delegou a responsabilidade de formação docente para o MEC, o que não ocorreu no período da pesquisa. Natal reduziu-se a orientar as escolas quanto à autoavaliação dos estudantes, sem que fosse compreendido como parte de um processo de consolidação da avaliação formativa na rede.

Concernente ao indicador "Utilização do tempo para assistência individual/coletiva aos alunos que apresentam dificuldade de aprendizagem", cabe destacar que todas as redes de ensino atribuíram pontuação 1, demonstrando a precariedade do atendimento prestado a esses estudantes nas redes pesquisadas. Nem todos os estudantes com dificuldades de aprendizagem, ou que fracassam na escola, são deficientes, da mesma forma, Sousa e Prieto (2007) lembram que nem todo estudante deficiente requer condições diferenciadas para aprender. As autoras (2007) consideram que, para se definir se um educando é especial, há a necessidade de diagnóstico consistente e criterioso, que subsidie tanto seu encaminhamento aos recursos educacionais especiais quanto à elaboração de proposta de ensino específica.

Uma grande variedade de questões interfere na aprendizagem do educando, além de ter ou não necessidades educacionais especiais. Isso pode levá-lo a necessitar, em algum momento, de ações específicas para que seu direito à aprendizagem se efetive. Ademais, a obrigatoriedade da participação em avaliações externas às escolas, a exemplo do Saeb e da Prova Brasil, que compõem o ldeb, tem incentivado as redes de ensino a desenvolver ações com o objetivo de atender às especificidades dos educandos para não comprometer os índices obtidos. 
Essa afirmação pode ser confirmada na justificativa do Município de Natal no que diz respeito a este indicador: "Considerando os dados apresentados pelo ldeb, que apontam a rede municipal com score crítico, faz-se necessário, por parte da SME, intervir nos anos/séries iniciais do Ensino Fundamental" (NATAL, 2007, s/p). Isso demonstra a importância que esse índice vem assumindo no cotidiano das escolas, estimulando o sistema a superar sua baixa qualidade educacional. O PAR informa, ainda, que a rede atende, com aulas de reforço, apenas 3\% do efetivo de estudantes por meio de "[...] oficinas pontuais, não atendendo às necessidades de assistência individual/coletiva permanente aos alunos" (NATAL, 2007, s/p).

Além desse reforço sistemático aos estudantes, o município de Natal presta assistência por meio de estratégias como o agrupamento produtivo e a enturmação dos estudantes. A informante 1 (2015) explica como acontece:

Em nossas formações a gente sempre orienta as escolas para que fizessem os agrupamentos produtivos, de acordo com o nível de aprendizagem dos alunos. E quando há um alto índice de alunos que precisam de um apoio pedagógico diferenciado, a gente chega a sugerir que haja enturmação desses alunos, e que determinado professor que tem mais o perfil de alfabetizador, fique duas vezes por semana com esses alunos que tem mais dificuldade, e as demais horas, fique com a sua turma de referência [...] (INFORMANTE 1, 2015).

Esse tipo de estratégia consiste em organizar os estudantes conforme seus potenciais de aprendizagem, seguindo o aporte teórico de pesquisas que enfoca a apropriação da linguagem escrita, com base em autores da perspectiva construtivista. No entanto, essas são ações anteriores ao PAR; por meio desse plano, a rede municipal comprometeu-se a prestar assistência aos estudantes oferecendo condições às escolas para que os professores os assistam. Os informantes, porém, não relatam novas ações além das que já vinham sendo desenvolvidas. Os sujeitos sentem-se responsáveis em melhorar os índices educacionais do município e isso se dá pela reorganização do próprio trabalho, sem que implique, por exemplo, a contratação de profissionais que atuem no contraturno, prestando assistência aos estudantes. Dessa forma, no Município de Natal, não há informações acerca de melhorias no que se refere à assistência individual e coletiva ao estudante propiciadas pelo PAR. 
Plano de Ações Articuladas: avaliação da aprendizagem e sua interface com a avaliação externa

Já o PAR do município de Acari informa que, embora se ofereça assistência individual ao estudante, isso não ocorria durante todo o ano letivo, devido à falta de pessoal (ACARI, 2007). Observa-se que tanto em Acari quanto em Natal havia algum tipo de assistência aos estudantes, mesmo não envolvendo todos os que demandavam ou que essa prática fosse esporádica. mesmo não ocorria nas demais redes que afirmavam que, antes da implementação do PAR, esses serviços eram inexistentes.

Assim, a análise do PAR dos municípios demonstram as ações desenvolvidas visando prestar assistência aos estudantes com dificuldade de aprendizagem: todos os municípios, com exceção de Natal, se propuseram a qualificar seus profissionais; todas as redes de ensino, à exceção de Acari, se comprometeram a investir nas condições das escolas, incluindo espaços, preparo de materiais, organização do tempo de assistência e formação de professores; os municípios de Natal e São José do Campestre ressaltaram a necessidade de acompanhar a implementação da proposta de assistência aos estudantes; e todos se dispuseram a divulgar esses serviços junto à comunidade (NATAL, 2007; ACARI, 2007; MOSSORÓ, 2007; SÃO JOSÉ DO CAMPESTRE, 2007; RIACHUELO, 2007).

Ao que parece, as ações empreendidas, durante o período da pesquisa (2007-201 1), não se mostraram efetivas, visto que não há relato dos informantes quanto aos investimentos nas condições escolares, tampouco no que tange às ações de formação de professores, visto que esse último quesito deveria contar com a assistência técnica do MEC. No município de Riachuelo, houve um discreto avanço quanto à assistência à aprendizagem estudantil, mas vale ressaltar a sua implantação em algumas instituições, conforme se observa no trecho a seguir:

Acho que aulas de reforço, né? Já têm algumas escolas que acontecem, pra esses alunos com baixa aprendizagem. Aí esse outro... Como esse que você falou, altas habilidades, acho que tem orientação. Até tanto que quando acontecem alunos que tem problemas de aprendizagem a gente, às vezes, até encaminha para o CRAS, pra aquelas psicólogas, essas coisas (INFORMANTE 2, 2015).

Assim, na rede de ensino de Riachuelo, os estudantes, com dificuldade de aprendizagem, ou procuram uma escola que possa atender às suas peculiaridades ou são encaminhados ao Centro de Referência de Assistência 
Social do Estado do Rio Grande do Norte, onde são oferecidos serviços de proteção social básica em áreas de vulnerabilidade e risco social (RIO GRANDE DO NORTE, 2015). A Informante 2 não faz menção à qualificação dos profissionais para prestar essa assistência, tampouco às condições escolares, além de parecer que a responsabilidade por esses alunos é da Assistência Social.

No município de São José do Campestre, existe a Secretaria Municipal de Educação que assessora os coordenadores-pedagógicos, visando ao atendimento aos estudantes com necessidades especiais de aprendizagem, conforme o trecho abaixo:

[...] eu me reunia com os coordenadores e eles traziam essas necessidades [...] fazia esse planejamento em cima daquilo que eles pudessem trabalhar com o professor, pra o professor trabalhar com aluno, pra ver qual era a melhor forma. Era através da música? É através da dança? Então, a gente trabalhava no sentido que fosse mais dinâmico pra eles, irem pra biblioteca [...] pesquisar, ler na internet, não fazer muito as atividades digitadas, mas escritas, porque melhorava a escrita dele [...] (INFORMANTE 04, 2015).

Embora a assessoria se dirigisse aos coordenadores escolares, caso houvesse dificuldades, os funcionários da Secretaria de Educação compareciam às escolas. Não existem informações, em nenhum dos municípios, acerca do curso de aperfeiçoamento que seria oferecido pelo MEC, para melhorar o atendimento aos estudantes com necessidades especiais de aprendizagem.

Já o município de Mossoró contratou psicopedagogos que atendem em algumas escolas polo, não havendo referência ao trabalho cotidiano, desenvolvido com os professores. A responsabilidade no atendimento aos estudantes deve ser assumida não só por especialistas, mas esses profissionais devem atuar de forma articulada com o conjunto dos professores que trabalha, cotidianamente, com os estudantes. Em Mossoró e Riachuelo, os informantes referem-se, apenas, à atuação de especialistas, que atuam em escolas polos ou em outros órgãos públicos estaduais. Um suporte mínimo ao trabalho dos professores, prestado pela Secretaria de Educação, para que atuem junto aos estudantes com dificuldade de aprendizagem foi observado, apenas, em Natal, Acari e São José do Campestre.

Para que os docentes atendam às necessidades de aprendizagem discentes necessitam de espaço adequado, recursos didáticos, formação 
continuada, tempo para planejamento incluído na carga horária de trabalho, entre outros requisitos, que thes possibilitam uma ação qualificada. Esses requisitos thes têm sido negados, comprometendo o direito à aprendizagem dos estudantes. No período desse estudo, o PAR pouco colaborou para a melhoria dessas condições, visto que muito do planejado não foi levado a efeito tanto por parte da esfera federal, que não proporcionou a formação docente acordada, quanto pelo fato de os municípios não terem realizado, como desejado, os investimentos que thes competiam.

A assistência educacional aos estudantes com dificuldade de aprendizagem demanda um processo de avaliação formativa capaz de prestar suporte à consecução da aprendizagem. A avaliação formativa privilegia o diagnóstico da aprendizagem, em função do desempenho dos estudantes, fornecendo ao professor informações acerca da distância do desempenho do educando em relação ao parâmetro desejado. Assim, visa à orientação necessária à superação de dificuldades, evitando problemas como a retenção e evasão escolar, que levam à distorção idade-série, considerada um grande problema da educação brasileira.

O documento "Iniciativa Global pelas crianças fora da escola: acesso, 140 permanência, aprendizagem e conclusão da Educação Básica na idade certa - direito de todas e de cada uma das crianças e dos adolescentes", publicado pela Unicef, em 2012, aborda a questão da distorção idade série no Brasil. O relatório (UNICEF, 2012 , p. 55) demonstra que, em 2010, 23,6\% dos estudantes brasileiros matriculados no ensino fundamental, encontram-se fora da faixa etária correspondente a sua série. Esse é um problema que se agrava à medida que aumenta a escolaridade.

Assim, o primeiro segmento do ensino fundamental apresenta $18,5 \%$ de distorção; o segundo segmento, 29,6\%; e o ensino médio, 34,5\% (Unicef, 2012 , p. 55). O quadro se agrava na Região Nordeste onde $26,6 \%$ da população em idade correspondente ao primeiro ciclo do ensino fundamental encontra-se fora de faixa etária correspondente; o mesmo acontece com $40,4 \%$ do segundo ciclo do ensino fundamental e $46 \%$ dos estudantes do ensino médio (UNICEF, 2012, p. 117).

Isso comprova a análise de Oliveira e Araújo (2005), acerca da permanência de intensa desigualdade regional no país no que se refere às taxas de aprovação, reprovação e evasão escolares. Eles afirmam que as ações 
implementadas, visando promover a correção do fluxo escolar, "[...] têm atingido apenas parcialmente o quadro de iniquidades da educação brasileira, fazendo com que o direito à educação cumpra apenas de forma precária e pouco efetiva o seu ideal igualitário e emancipador" (OLIVEIRA; ARAÚJO, 2005, p. 13).

Dessa forma, torna-se imprescindível o desenvolvimento de ações que tanto garantam a aprendizagem dos estudantes, quanto colaborem para eliminar as distorções idade-série. Com esse propósito, por meio do PAR, as redes de ensino desenvolveram ações visando à regularização do fluxo escolar. Somente três redes de ensino pesquisadas desenvolveram ações de correção de fluxo escolar: Natal, São José do Campestre e Riachuelo.

Mossoró (2017) alega não haver necessidade de ações desse tipo, visto que existiam ações com esse fim, em algumas escolas. Acari (2007) justifica que desenvolve políticas próprias para combater a distorção idade-série. Por essa razão, o "[...] município, em dois anos consecutivos, foi premiado, pelo governo do Estado, por apresentar o menor índice de distorção idade-série (Prêmio "Mérito Potiguar de Educação") (ACARI, 2007, s/p)".

Nesse município, a Secretaria de Educação criou um programa de aceleramento da aprendizagem, a que se seguia a reclassificação dos estudantes fora de faixa, conforme explica a Informante 2 (2015):

[...] quando a gente via que estava com distorção idade-série a gente fazia um trabalho mais voltado para a questão do aceleramento deles. [...] E quando a gente via que ele fazia as provas e que estava no nível que poderia ser reclassificado, a gente também trabalhava (INFORMANTE 2, 2015).

Além do trabalho que visava ao aceleramento do estudante fora de faixa, aqueles que completavam 15 anos eram, imediatamente, encaminhados para Educação de Jovens e Adultos (EJA). Isso é permitido pelo art. 38 da Lei de Diretrizes e Bases da Educação Nacional, Lei n 9.694 (BRASIL, 1996), de 20 de dezembro de 1996. Não obstante, tem levado a que muitos jovens sejam retirados da escolaridade regular e encaminhados para a EJA, que possui um tempo de escolaridade menor e atende a um público bastante diversificado. Isso pode ser desfavorável ao seu desenvolvimento pessoal.

Os municípios de Natal, São José do Campestre e Riachuelo implementaram programas de correção de fluxo contando com a assistência técnica 
Plano de Ações Articuladas: avaliação da aprendizagem e sua interface com a avaliação externa

do MEC. Essa assistência foi prestada com base em parcerias com organizações não governamentais, o que retrata o movimento de "[...] minimização do Estado na condução das políticas sociais, que ficam dependentes apenas das leis do mercado, tido como dinâmica própria da esfera do privado" (SEVERINO, 2005, p. 33-34).

Por meio dessa assistência, cada município buscou firmar parcerias público-privada, visando implementar programas em consonância com a concepção de educação e de avaliação que afirmavam seguir. Dessa forma, os municípios de Natal e Riachuelo, que buscam desenvolver uma avaliação de característica formativa e contínua, implementaram o programa de correção de fluxo proposto pelo Geempa (Grupo de Estudos sobre Educação, Metodologia da Pesquisa e Ação), conforme mostra o informante 2, de Riachuelo:

O MEC [...] fornecia o material para o aluno e para o professor e pagava a formação ao instituto. [...] nós nos reunimos com os assessores pedagógicos e discutimos as três propostas ofertadas pelo MEC, nós [...] optamos pelo GEEMPA, porque se identifica com os nossos referenciais, com as concepções que nós temos na rede municipal de aprendizagem de avaliação (INFORMANTE 2, 2015).

Conforme o site da instituição, o Geempa consiste em uma organização privada, sem fins lucrativos, que apoia Universidades, Secretarias de Educação e Ministério de Educação na realização de projetos de pesquisa e ações que visam à melhoria da qualidade educacional (GEEMPA, s/d). Sua proposta educacional baseia no pós-construtivismo e na construção teórica de autores como Piaget, Vygotski, entre outros (GEEMPA, 2017, s/d), que se afina com o referencial de avaliação formativa que as redes de ensino buscavam implementar. $\bigcirc$ informante 1, de Natal, relata acerca da assistência recebida:

[...] foi trabalhado com ênfase para que o aluno voltasse a acreditar que ele é capaz e [...] para que ele não se afastasse da escola. Realmente, tivemos um sucesso bem significativo de envolvimento deste aluno no processo, com muitos alunos alfabetizados. [...] Esse trabalho iniciava com uma formação de cinco dias que o Geempa vinha e realizava com os professores [...], manhã tarde e noite. No decorrer do ano, o Geempa vinha e fazia o assessoramento que durava dois dias, em que o professor trazia os resultados dos seus trabalhos, as falas dos alunos, para que, em cima desse resultado, 
discutissem os encaminhamentos de como proceder com aquela turma, com aquele aluno, e o material era entregue ao professor (INFORMANTE 1, 2015).

Conforme relatado, a assistência técnica do MEC, efetivada por meio da parceria público-privado do Geempa preparou os professores para trabaIhar com estudantes com distorção idade-série, abordando não só conteúdos, mas também a autoestima. Além da formação inicial e do material didático utilizado pelo professor, havia o acompanhamento do trabalho desenvolvido, prestando o suporte necessário às intervenções pedagógicas dos professores e às mudanças requeridas na prática profissional tendo como base a avaliação formativa, que colaborou para o sucesso relatado pela Informante 1 .

Pertinente ao município de São José do Campestre, quem prestou a assistência técnica foi o Instituto Alfa e Beto. $O$ Instituto se propõe a desenvolver educação de qualidade, pois "[...] crianças e jovens educados produzem mais e melhor, são conscientes de seus direitos e deveres e estão aptos a contribuir ativamente para a construção de uma economia sustentável e justa" (INSTITUTO ALFA E BETO, s/d). Essa empresa, que prestou assessoria educacional ao município, está, consequentemente, comprometida não com a formação humana, mas com a formação de valores e com a construção de conhecimentos, necessários ao desenvolvimento da sociedade capitalista. Embora tenha prestado serviço no município, os informantes não relataram aspectos relacionados à qualidade dos serviços prestados tampouco acerca do referencial de avaliação adotado pelo Instituto.

\section{Algumas considerações...}

Este estudo evidenciou que o PAR se insere no contexto de mudanças na regulação educacional, como parte da redefinição do papel do Estado, que vem assumindo a concepção de Avaliador. O PAR, enquanto parte dessas políticas que visavam dinamizar as relações de colaboração entre os entes federados, objetivando a melhoria da qualidade educacional no país, tem induzido os municípios a elaborar planos de ações para as redes de ensino.

A qualidade que se pretende implementar por meio dessas ações, no entanto, distancia-se de uma concepção transacional e negociada, visto que a elaboração da proposta do PAR não contou com a participação dos 
Plano de Ações Articuladas: avaliação da aprendizagem e sua interface com a avaliação externa

entes federados. Tampouco as redes de ensino têm liberdade de propor ações, mas devem, após elaborar diagnóstico das necessidades, selecionar, entre as ações preestabelecidas, aquelas que serão implementadas.

Em razão do restrito envolvimento dos entes federados na formulação do PAR, determinadas municipalidades não se comprometem com a efetivação das ações e estratégias registradas no PAR. Além disso, apesar do diagnóstico apontar a necessidade de intervenção em determinadas situações, selecionam-se indicadores e ações que demandam menores investimentos, o que afeta o alcance da colaboração que se deseja efetivar, tendo em vista a melhoria da qualidade educacional.

O PAR induziu as redes de ensino a se posicionarem acerca do referencial de avaliação que adotam, e os discursos dos profissionais das Secretarias de Educação denotam tanto a valorização da avaliação contínua, de cunho formativo, quanto as dificuldades de congregar a prática dos profissionais das escolas segundo essa concepção. Mesmo com essa dificuldade, apenas dois municípios se dispuseram a implementar ações referentes a esse indicador, no entanto, nessas redes, o suporte profissional e investimentos necessários não foram prestados a contento, tampouco a assistência técnica do MEC ocorreu no tempo previsto, comprometendo o alcance de determinadas ações.

Os indicadores referentes à assistência individual/coletiva aos estudantes com dificuldades de aprendizagem e correção de fluxo escolar, embora importantes para a garantia do direito à aprendizagem, visam, em particular, a melhoria do ldeb. O PAR não se refere a ações de autoavaliação institucional que poderiam colaborar para que as escolas analisassem a própria ałuação, tendo em vista superar seus desafios. As atuais políticas de avaliação do país não articulam avaliação externa e autoavaliação institucional como subsídio à planificação de melhorias educacionais, mas as ações avaliativas têm o propósito de informar à sociedade acerca dos resultados dos investimentos e de responsabilizar os profissionais por eles.

Quanto à utilização do tempo para assistência individual/coletiva aos alunos que apresentam dificuldade de aprendizagem, todas as redes demonstraram precariedade no atendimento prestado aos estudantes. Assim, comprometeram-se a investir nas condições das escolas, incluindo espaços, preparo de materiais, organização do tempo de assistência e formação de professores. As ações desenvolvidas, porém, referem-se a mudanças na 
organização do trabalho pedagógico, sem que as condições necessárias fossem conferidas.

No que concerne à política específica de correção de fluxo, somente três redes de ensino pesquisadas desenvolveram ações nesse sentido, por meio de parceria público-privado, que denota o processo de minimização da intervenção estatal na educação. Essas instituições difundem, por meio de sua atuação, concepções e valores próprios que tanto podem promover a formação humana quanto legitimar a continuidade de relações de exploração do capital. Outrossim, observa-se um movimento de retirada dos jovens da escolaridade regular para encaminhá-los à EJA, para que os índices escolares expressos no ldeb não sejam prejudicados. Sob a alegação de correção do fluxo escolar, desconsideram-se as necessidades educacionais dos jovens estudantes que passam a contar com um tempo de escolaridade menor e aprender em meio a um público bastante diversificado. Isso pode comprometer, sobremaneira, seu desenvolvimento pessoal.

Em suma, constatou-se, nos documentos analisados e nas informações prestadas pelos entrevistados, a presença da responsabilização das instituições de ensino em relação aos seus resultados sem apontar as políticas e as condições materiais para que a "qualidade" e o direito à aprendizagem se efetivem. A responsabilidade, em geral, incide sobre os profissionais, sem que os sistemas arquem com as condições necessárias à construção da melhoria da qualidade educacional.

Há uma preocupação excessiva com o alcance dos índices e, para solucionar o problema, em alguns municípios, a solução tem sido o estabelecimento de parceria público-privada, por meio da assessoria do MEC. Tal iniciativa se insere na perspectiva do quase-mercado na educação, fundamentado em princípios e critérios de eficiência, produtividade e competitividade, que se distancia de uma concepção de qualidade educacional socialmente negociada e referenciada.

\section{Notas}

$1 \bigcirc$ programa WordSmithTools é uma ferramenta composta por programas integrados ('suíte') destinados à análise linguística. Esse software realiza análises baseadas na frequência e na co-ocorrência de palavras. Permite processar arquivos do corpusantes da análise propriamente dita. 
Plano de Ações Articuladas: avaliação da aprendizagem e sua interface com a avaliação externa

2 A noção de quase-mercado significa a introdução de concepções de gestão privada nas instituições públicas, sem, no entanto alterar a essência das mesmas. Diferencia-se do mercado nos aspectos conceituais e operacionais e é utilizada no setor público como mecanismo indutor de melhorias.

\section{Referências}

ACARI. PAR analítico do Município de Acari - RN (2007-201 1). SIMEC - Sistema Integrado do Ministério da Educação/SE - Secretaria Executiva, 2007.

AURELIANO, Francisca Edilma et al. Descritores: Avaliação em educação; Concepções de política; Avaliação de políticas públicas; Conceitos; Dimensões e Indicadores de qualidade. Natal: UFRN, 2014.

BOGDAN, Robert C.; BIKLEN, Sari Knopp. Investigação qualitativa em educação: uma introdução à teoria e aos métodos. Tradução Maria João Alvarez, Sara Bahia dos Santos e Telmo Mourinho Baptista. Porto: Porto Editora, 1997.

$\mathrm{BONDIOLI}$, Ana. O projeto pedagógico da creche e sua avaliação: a qualidade negociada. Campinas: Autores Associados, 2004.

BRASIL. Lei n 9.394, de 20 de dezembro de 1996. Estabelece as diretrizes e bases da educação nacional (LDB). Diário Oficial [da] União, Poder Executivo, Brasília, DF, 23 de dezembro de 1996. Seção 1, p. 27833.

Parâmetros Curriculares Nacionais. Ensino Fundamental. Brasília: MEC/SEF, 1997

O Plano de Desenvolvimento da Educação: razões, princípios e programas. 2007a. Disponível em: <http://portal.mec.gov.br/arquivos/pdf/livromiolov4.pdf>. Acesso em: 15 abr. 2014.

Decreto $\mathbf{n}^{\circ} \mathbf{6 . 0 9 4}$, de 25 de abril de 2007. Dispõe sobre a implementação do Plano de Metas Compromisso Todos pela Educação. Casa Civil, 2007b. Disponível em: http://www.planalto.gov.br/ccivil_03/_ato2007-2010/2007/decreto/d6094.ht m. Acesso em: 20 mar. 2017.

BRASIL. Ministério da Educação. Orientações gerais para aplicação dos instrumentos para formulação dos Planos de Ação Articuladas (PAR) dos municípios. Brasília: Ministério da Educação, 2008. 
CRUZ, Gersonita Paulino de Sousa. A política de avaliação da aprendizagem da Secretaria Municipal de Educação de Natal no contexto do PAR 2007-2011. 2015. 181 f. Dissertação (Mestrado em Educação) - Programa de Pós-Graduação em Educação, Universidade Federal do Rio Grande do Norte, Natal, 2015.

DEROUET, Jean Louis. Governança e avaliação no sistema educativo francês: em busca de uma avaliação pluralista? Educação em Foco: Avaliação de Sistemas Educacionais, Juiz de Fora, v. 6, n. 2, p. 33-48, set./fev. $2001 / 2002$.

DIAS SOBRINHO, José. Campo e Caminhos da Avaliação: a avaliação da educação superior no Brasil. In: FREITAS, Luiz Carlos (Org.). Avaliação: construindo o campo e a crítica. Florianópolis: Insular, 2002.

Cortez, 2003.

Avaliação: políticas educacionais e reformas da educação superior, São Paulo:

FERNANDES. Domingues. Avaliar para aprender: fundamentos, práticas e políticas. Editora UNESP: São Paulo, 2009.

FERNANDES, Reynaldo. Índice de Desenvolvimento da Educação Básica (ldeb). 26 ed. Brasilia: Inep, 2007.

FREITAS, Luiz Carlos de. Eliminação Adiada: $\bigcirc$ acaso das classes populares no interior da escola e a ocultação da (má) qualidade do ensino. Educação \& Sociedade, Campinas, v. 28, n. 100, p. 965-987, out. 2007.

Responsabilização, meritocracia e privatização: conseguiremos escapar ao neotecnicismo? In: CONGRESSO BRASILEIRO DE EDUCAÇÃO, 3., 2011 , Campinas. Anais.. Campinas: Centro de Estudos Educação e Sociedade, 2011.

GEEMPA. Grupo de Estudos sobre Educação Metologia de Pesquisa e Ação. s/d. Disponível em: https://www.educaedu-brasil.com/centros/geempa-grupo-de-estudos-sobre-educacao-metologia-de-pesquisa-e-acao-uni3227. Acesso em: 1ªgo. 2017.

INFORMANTE 1, Entrevista. Natal (RN), maio. 2015.

INFORMANTE 2, Entrevista. Riachuelo (RN), maio 2015.

INFORMANTE 4, Entrevista. São José do Campestre (RN), maio 2015.

INFORMANTE 10, Entrevista. Mossoró (RN), maio. 2015.

INSTITUTO Alfa e Beto. Quem somos. Disponível em: http://www.alfaebeto.org.br/ sobre/\#quem-somos. Acesso em: $1^{\circ}$ ago. 2017. 
MINAYO, Maria Cecília de Souza. O desafio do conhecimento: pesquisa qualitativa em saúde. 6. ed. São Paulo: Hucitec; Rio de Janeiro: Abrasco. 1999.

MOSSORÓ. PAR analítico do Município de Mossoró - RN (2007-201 1). SIMEC - Sistema Integrado do Ministério da Educação/SE - Secretaria Executiva, 2007.

NATAL. PAR analítico do Município de Natal - RN (2007-20 1 1). SIMEC - Sistema Integrado do Ministério da Educação/SE - Secretaria Executiva, 2007.

OlIVEIRA, Romualdo Portela de; ARAÚJO, Gilda Cardoso de. Qualidade do ensino: uma nova dimensão da luta pelo direito à educação. Revista Brasileira de Educação, Rio de Janeiro, n. 28, p. 5-24, jan/abr. 2005.

RAVITCH, Diane. Vida e morte do grande sistema escolar americano: como os testes padronizados e o modelo de mercado ameaçam a educação. Tradução Marcelo Duarte. Porto Alegre: Sulina, 2011.

REIS, Isaura Machado. Governância da educação em Portugal: $\bigcirc$ local e os modos de regulação da oferta educativa $\left(2^{\circ}\right.$ e $3^{\circ}$ ciclos do ensino básico e ensino secundário). 2009. Tese (Doutorado em Educação) - Universidade da Beira Interior, Covilhã, 2009. 476 p.

RIACHUELO. PAR analítico do Município de Riachuelo - RN (2007-201 1). SIMEC - Sistema Integrado do Ministério da Educação/SE - Secretaria Executiva, 2007.

RIO GRANDE DO NORTE. Secretaria de Estado do Trabalho e Assistência Social. Centro de Referência de Assistência Social (CRAS). 17 mar. 2015. Disponível em: http://www.seas. rn.gov.br/Conteudo.asp?TRAN=|TEM\&TARG=69449\&ACT=null\&PAGE=0\&PARM=null\&LBL =Programas. Acesso em: $1^{\circ}$ ago. 2017.

SEVERINO, Antônio Joaquim. O público e o privado como categoria de análise em educação. In: LOMBARDI, José Claudinei; JACOMELI, Mara Regina; SILVA, Tânia Mara Teixeira da (Org.). O público e o privado na educação brasileira: concepções e práticas educativas. Campinas: Autores Associados; HISTEDBR; Unisal, 2005.

SÃO JOSÉ DO CAMPESTRE. PAR analítico do Município de São José do Campestre RN (2007-201 1). SIMEC - Sistema Integrado do Ministério da Educação/SE - Secretaria Executiva, 2007.

SORDI, Mara Regina Lemes de; SOUZA, Eliana da Silva. A avaliação institucional como instância mediadora da qualidade da escola pública: a Rede Municipal de Educação de Campinas como espaço de aprendizagem. Campinas: Millenium, 2009. 
SOUSA, Sandra Maria Zákia Lian; PRIETO, Rosângela Gavioli. Educação especial. In: OLIVEIRA, Romualdo Portela de; ADRIÃO, THERESA (Org.). Organização do ensino no Brasil: níveis e modalidades na Constituição Federal e na LDB. 2. ed. São Paulo: Xamã, 2007.

SOUSA, Sandra Maria Zákia Lian. Avaliação da educação básica e gestão de políticas públicas: uma relação em construção. In: ENCONTRO NACIONAL DE DIDÁTICA E PRÁTICA DE ENSINO, 14., 2008, Porto Alegre. Anais...Porto Alegre: Pontifícia Universidade Católica do Rio Grande do Sul, 2008.

UNICEF. Iniciativa global pelas crianças fora da escola - Brasil: acesso, permanência, aprendizagem e conclusão da Educação Básica na idade certa - Direito de todas e de cada uma das crianças e adolescentes. Brasília: UNICEF, 2012.

Profa ${ }^{a}$. Dr ${ }^{a}$. Lucia de Fátima Valente Universidade Federal de Uberlândia | Campus Pontal Faculdade de Ciências Integradas do Pontal Programa de Pós-Graduação em Educação Grupo de Estudos e Pesquisas em Política, Formação Docente e Práticas Educativas

- Geppope

E-mail | valentelucia@yahoo.com.br

Prof ${ }^{a}$. Dr ${ }^{a}$. Luciane Terra dos Santos Garcia Universidade Federal do Rio Grande do Norte | Campus Natal Centro de Educação Departamento de Fundamentos e Políticas da Educação

Programa de Pós-Graduação em Educação Grupo de Pesquisa Políitica e Gestão da Educação E-mail | ltsgarcia@gmail.com

Profa. Ms. Gilneide Maria de Oliveira Lobo Universidade Federal do Rio Grande do Norte Secretaria Municipal de Educação do Município de Mossoró 
Artigo

Plano de Ações Articuladas: avaliação da aprendizagem e sua interface com a avaliação externa

Grupo de Pesquisa Política e Gestão da Educação

E-mail | gm.lobo@hotmail.com

Recebido 12 dez. 2017

Aceito 19 fev. 2018 